\title{
Implement of zoning in order to evaluate the establishment of the airports using integrating MCDM methods and noise pollution modeling softwares
}

\author{
Maryam Kiani Sadr $^{* \mathbb{(}}$, Kobra Melhosseini Darani ${ }^{2}{ }^{\circledR}$, Hamta Golkarian $^{3}$, Amir $^{\circledR} \operatorname{Arefian}^{4}$ \\ ${ }^{1}$ Department of Environment, College of Basic Sciences, Hamedan Branch, Islamic Azad University, Hamedan, Iran \\ ${ }^{2}$ Environmental Sciences Department, Faculty of Natural Resources and Environment, Malayer University, Malayer, Iran \\ ${ }^{3}$ Department of Civil, Environmental and Architectural Engineering, School of Environmental Engineering, Padua, Italy \\ ${ }^{4}$ Department of Civil Engineering, Shahryar Branch, Islamic Azad University, Shahryar, Iran
}

\begin{abstract}
Background: Finding the best location for the airport reduces the negative effects of construction and its activity on the environment. This study aimed to evaluate the establishment of the airports (Mehrabad and Imam Khomeini airports) in Tehran province through integration of multi-criteria decision making (MCDM) methods and noise pollution modeling software.

Methods: The criteria for zoning the airports were determined using Delphi method, and then, were weighed using analytic network process (ANP). One of the criteria was noise pollution. The computer aided noise abatement (CadnaA) software was used to map the noise level at the airports. The geographic information system (GIS) software and weighted overlay method were used to zone Tehran province for construction of the airports. The percentage of voice annoyance was defined according to the questionnaire provided by the International Commission on the Biological Effects of Noise (ICBEN). Results: Prioritization between the selected criteria using ANP and TOPSIS showed that the most important criteria are the land use (0.069) and the distance from the city $(0.0598)$, respectively. The highest percentage of highly annoyed (\%HA) persons was reported at both airports at Lden levels above $70 \mathrm{~dB}$.

Conclusion: According to the results of this study, the location of Mehrabad and Imam Khomeini airports is considered $60 \%$ and $18 \%$ inappropriate, respectively. The results introduce a set of criteria that determines compatibility rate of different activities around the airports based on the noise levels. Finally, it is recommended to study the correlation between aircraft noise pollution indicators in other airports of Iran and design a local model for the whole country.

Keywords: Noise, Geographic information systems, Airports, Environmental indicators, Software Citation: Kiani Sadr M, Melhosseini Darani K, Golkarian H, Arefian A. Implement of zoning in order to evaluate the establishment of the airports using integrating MCDM methods and noise pollution modeling softwares. Environmental Health Engineering and Management Journal 2020; 7(2): 97-105. doi: 10.34172/EHEM.2020.12.
\end{abstract}

Article History: Received: 24 March 2020 Accepted: 21 June 2020 ePublished: 16 July 2020

\section{Introduction}

Problems and challenges arising from the integration of the airport functions in the context of urban space are complex issues $(1,2)$. Airports can have profound effects on land use and activities in the area, which may be economic, developmental, visual, etc $(3,4)$. The environmental impacts of airports are considerable within the local area $(5,6)$. During the construction of an airport, some operations like land use changes and removal of vegetation are considered as the necessary changes to create a suitable area for this kind of land use. Other environmental factors like air pollution, industrial wastewater and domestic wastewater generated from the airports, and even the disruption of the existing environmental balance should be noticed. The share of airports in the production of noise in urban societies varies depending on the geographical location of the airports and other parameters like economic development and the presence of other means of transportation $(7,8)$. Noise as an undesired or harmful sound has short-term effects like sleep disorders $(9,10)$ or increased stress, fatigue, and neural stimulations. It also affects human activities such as learning, working, and sleep quality (3-6). This means that noise pollution reduces the quality of human life 
$(11,12)$. A healthy environment without undesired sounds is simply removed from the human life $(13,14)$. Aviation industry is a dynamic and fast-paced industry that fits into the needs of today's societies (15). The aviation industry plays a key role in local and national economy (16-18). Noise pollution is considered as an important factor in any kind of project for construction and development of airports (19-21). The negative effects of airplanes include behavioral and psychological disorders such as irritability or sleep disorders (22-24). Airport authorities should also have eligible potentials for land acquisition, controlling the impacts of noise, as well as proper knowledge on noise pollution estimation methods (25-28). To confront the above-mentioned problems, a proper zoning procedure for airport developments considering all environmental criteria can be a good solution (29-31). As mentioned before, air pollution is the most important environmental problem at airports that should be considered in both development and construction procedures. The development of silent engines and modification of aviation patterns have significant effects in reducing noise pollution. Another effective strategy to reduce the pollution is to provide comprehensive plans to use the airports surrounding areas. Mahashabde et al assessed the environmental impact of aircraft noise and emissions (32). For this purpose, first, the noise effects, air and aviation in general were investigated, then, it was discussed how environmental impact assessment and its ambiguities could provide a more comprehensive assessment of aviation environmental policies (32). Kroesen et al investigated the effects of transportation noise annoyance on residential satisfaction in the Netherlands (33). They determined the correlation between target variables, sound annoyance, and residents' satisfaction using a structural model and SPSS software. Babisch examined various factors causing the residents' annoyance in the study area and reported that the effect of noise caused by aircrafts is greater than that caused by traffic, railway, and construction activities. They also found that the type of aircraft, the size, shape, and location of airport, and airport runways have created many problems for the residents. In addition, the results have shown that the effects of noise pollution depend on noise level, noise time span, runways for landing and taking off, number and type of flight operations, aviation method, the use of airport runway system accompanied with aviation plan, different timing, season and climate conditions (34).

The present study was conducted to identify and prioritize the effective criteria for the establishment of Mehrabad and Imam Khomeini airports in Tehran province, and examine the spatial desirability of the airports. For the first time, the criteria for zoning the airports were determined according to the criteria presented by the reputable International organizations. Using Delphi method and emphasizing on the analysis of sound measurement parameters, percentage of annoyance caused by noise levels was determined. On the other hand, multi-criteria decision making (MCDM) methods and weighted overlay in geographic information system (GIS) were used to investigate the spatial status of Imam Khomeini and Mehrabad airports in Tehran province. The computer aided noise abatement (CadnaA) model was used to calculate sound levels.

Guidelines and effective criteria for zoning airports are provided by the reputable International organizations such as the Federal Aviation Administration (FAA) and International Civil Aviation Organization (ICAO), which were studied in this research. Unfortunately, there are no specific guidelines and criteria for the establishment of airports in Iran. Therefore, in the present study, the criteria and suitability of different zones for establishment of airports in Tehran province were investigated and introduced. In this study, the integration of MCDM and GIS methods along with sound field measurement and CadnaA model were used. MCDM is a mathematical model that refers to a problem-solving approach, which is used to select an option from a limited number of options. In this study, in order to achieve more efficient decisions to weight zoning criteria properly and select the best location for establishment of airports, a combined approach (ANP-TOPSIS) was used to compensate their weaknesses and strengths (35-37). Compensatory methods such as TOPSIS allow trade-offs between criteria, where a poor result in one criterion can be negated by a good result in another criterion. TOPSIS is the Technique for Order of Preference by Similarity to Ideal Solution (38-40). The analytic network process (ANP) is used in multi-criteria decision analysis. It consists of hierarchies, clusters, elements, and their relations (41-43). Therefore, in this study, in order to profit the advantages of both techniques in ranking and selecting the best option, a combined method (ANP-TOPSIS) was used. These methods are used to evaluate the suitability of different areas of Tehran province for establishment of airports.

\section{Materials and Methods}

Study area

Tehran province with an area of about $12981 \mathrm{~km}^{2}$ is situated between 34 to 36.5 degrees' north latitude and 50 to 53 degrees' east longitude. The population of the province in 2016 was estimated around 13267637 people. The capital of this province is Tehran, which is the capital of Iran. Tehran province has two International airports, Imam Khomeini and Mehrabad airports.

Imam Khomeini International airport is located on a 14000-hectare site, $30 \mathrm{~km}$ far away from Tehran, in the administrative and political area of Shahr-e Rey (Fashafoyeh section), between Tehran-Qom freeway. Since June 2019, the airport has two active terminals. Mehrabad International Airport is another international airport in Tehran, which was built in 1938 in the western part of Tehran. The location of these two airports in Tehran province is shown in Figure $1(44,45)$. 
Using Delphi method and emphasizing on the analysis of sound measurement parameters, the percentage of annoyance caused by sound levels was determined. On the other hand, MCDM methods and weighted overlay in GIS were used to investigate the spatial status of the airports in Tehran province. The CadnaA model was used to calculate sound levels.

Guidelines and effective criteria for zoning the airports provided by the reputable international organizations such as the FAA and ICAO, were studied in this research. Unfortunately, there are no specific guidelines and criteria for establishment of airports in Iran.

In this study, first, different airport location criteria published by the reputable global organizations such as ICAO and FAA were studied. According to the criteria and using Delphi method, a set of zoning criteria was determined. The ANP was conducted using Super Decisions software. Then, ArcGIS software was used to mathematically measure the layers. At this stage, according to the weight of the criteria selected by ANP, Weighted Overlay was performed, and then, prioritization was done between suitable places for establishment of the airports using TOPSIS method. Simultaneously, sound parameters were measured around Mehrabad and Imam Khomeini airports. The CadnaA model was used to prepare the sound zoning map of the airports. Then, the questionnaire presented by the International Commission on the Biological Effects of Noise (ICBEN) was used to study the sound annoyance levels caused by the airports. The questionnaire is related to the monitoring and evaluation of environmental sounds. The results of this stage were used to determine the land uses compatibility criteria with the sound levels in the airports surrounding areas in Iran. The procedures are described in the following sections.

Data collection using Delphi method and a combined method (ANP-TOPSIS)

In this survey, firstly, different criteria published by the important international organizations like ICAO and FAA to estimate the location for establishment of the airports, were studied. The Delphi method was used to determine the criteria. The Delphi method is an approach that collects the opinions of the experts without any communication between them (46). Using the Delphi method, the criteria were introduced and evaluated in three steps by a panel of experts. In the first stage, the Delphi panel members were asked individually to introduce their criteria by giving their reasons. In the second stage, a table consisted of a set of the selected criteria, which were introduced based on the feedback reported by the panel in the first step, was sent to the experts and they were asked to rate and rank the criteria. In the third stage, a summary of the second stage questionnaires was provided as a feedback report for the Delphi panel. They were asked to rank the selected indicators for each criterion considering the opinions of other experts. At this stage, the presented model contains

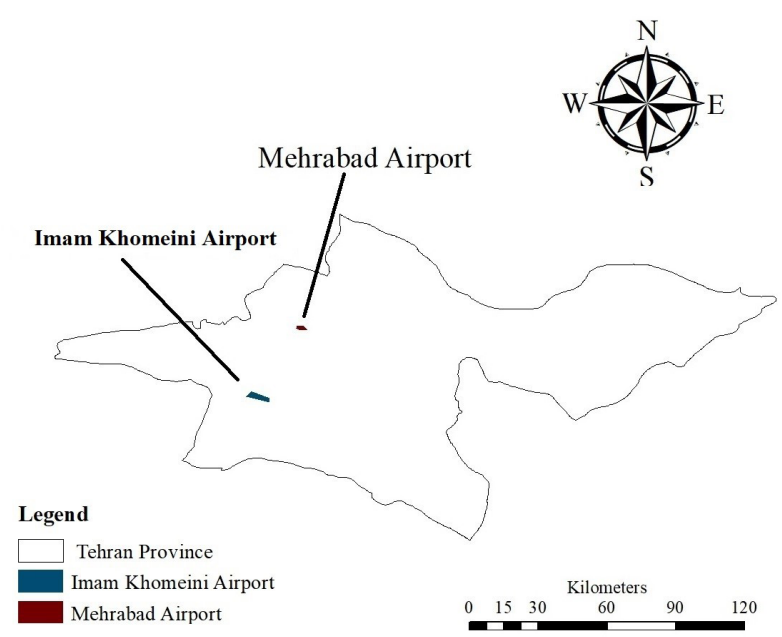

Figure 1. Location of Imam Khomeini and Mehrabad airports in Tehran province.

the standardized parameters that have been determined by the Delphi panel using consensus. Along with the model of priority of the criteria, the ANP method can be used to estimate the weight of the criteria. It is a powerful and flexible tool for the quantitative and qualitative investigation of multi-criteria problems through pairwise comparison as its main characteristic (41).

The TOPSIS method was also used to determine the weight of the criteria and prioritize the appropriate locations. The TOPSIS is a powerful technical decisionmaking method for prioritizing options with the shortest distance of the selected option to the ideal answer and the longest distance to the inefficient answer. In this method, double comparison matrix was used to determine the weight of the criteria. Then, this matrix entered in Expert Choice software version 11 for the final weighing of the criteria and determining adjustment coefficients. In this research, TOPSIS algorithm was capable of considering all aspects, including issues such as profit and cost, priority and weight of the criteria compared to each other, etc. It also measures the options relative to each other and sorts them in a rational way.

The ICAO has introduced the following criteria for zoning airports:

- Aviation operations

- How to develop the airports surrounding area

- Climate conditions (fog, mist, smoke, changes in climate pattern, prevailing wind, rainfall, snow, low clouds, and turbulence)

- Access to road transportation system

- Availability of land (sufficient land to expand existing airports or create new ones): To evaluate this factor, studies regarding aviation, land, roads, topographic maps, aerial photographs, etc are needed. Studying the topographic maps identifies areas with appropriate slope and drainage. Geological maps show the distribution of soil and rock types. In addition, the 
availability of construction materials, the value of relevant land and their use (agricultural, industrial, residential, etc) should also be studied.

- Topography: It has an important impact on the construction costs, including drilling, embankment, drainage, and so on.

- Environment: Studying wildlife reservoirs, migration areas for wildlife and birds, noise-sensitive areas such as hospitals and schools.

- Existence of other airports and availability of airspace in the area

- Access to facilities for airport establishments (water, electricity, gas, fuel, plumbing, and telephone) (47).

The FAA has also provided an APPENDIX E added to FAA B6-5070/150 on zoning the airports. It states that a screening process is needed to locate airports. All primary locations considered for this development must be evaluated by a set of basic criteria to identify their weaknesses. Screening factors may include topography, natural or man-made barriers, airspace, accessibility, environmental impacts, and development costs. Also, one of the best references that plans for noise pollutions caused by airplanes in locating new airports is the Federal Aviation Regulations (FAR) part 150 (Sound Adaptation Program) (48). After introducing the airport locating criteria by the Delphi method, the criteria weights were determined by the ANP method and Super Decisions software version 2.10. Then, ArcGIS software version 10.4 was used for weighted overlay of criteria layers.

\section{CadnaA model and ICBEN questionnaire}

At this phase, according to the weights of the criteria selected by the ANP, weighting process was completed and the appropriate location for establishment of an airport in Tehran was studied. Along with these steps, sound parameters around Mehrabad and Imam Khomeini International airports in Tehran province were measured and the noise level of these two airports was mapped using CadnaA model.

CadnaA is a software for estimating the environmental noise assessment in the vicinity of sound generating sources such as airports and aviation sites. This program communicates with all components and elements that affect the creation and dispersion of the sound. CadnaA provides calculation and documentation of the sound level according to the national and international guidelines and regulations. It displays the results by drawing a sound domain and providing colored maps of the sound level. In other words, CadnaA produces the maps of sound distributions from their sources and evaluates them. Then, the ICBEN questionnaire was used to examine the annoyance level of the noise caused by the airports. Using the questionnaire, the environmental sounds are monitored and evaluated. The questionnaire has been designed by the ICBEN and its results can be used for the international comparisons and reviews $(49,50)$. The questionnaire includes some questions regarding aircraft noise assessment and a series of general questions $(51,52)$.

\section{Results}

Super Decisions and TOPSIS software were used to determine the weight of the criteria. The weights related to the airport zoning criteria are presented in Table 1 . The environmental criteria affecting airport location were co-scaled in five classes, and then, Super Decisions and TOPSIS software were used to determine the weight of the criteria. Weighted Overlay and TOPSIS methods were used to integrate the layers and MCDM methods. Figure 2 shows the output results of the weighted overlay and TOPSIS methods in locating airports in Tehran province. Based on this method, a map for establishment of an airport was obtained using the weight of layers. In this map, which is made by overlaying of 22 criteria, there was no location as the most suitable zone (5 grades) for airport establishment. All zones presented in the map were categorized into four categories including inappropriate (grade 1), weak (grade 2), moderate (grade 3 ), and suitable (grade 4). The results of field measurements of sound and noise zoning by CadnaA model in Imam Khomeini and Mehrabad airports are presented in Figures 3 and 4. The outputs of these maps were integrated with the results of the questionnaires distributed among residents regarding the noise annoyance levels.

Table 1. Weights for airport zoning criteria

\begin{tabular}{lcc}
\hline Criteria & ANP & TOPSIS \\
\hline Erodibility & 0.052 & 0.0413 \\
Soil fertility & 0.061 & 0.052 \\
Soil texture & 0.055 & 0.0445 \\
Climate & 0.049 & 0.0586 \\
Height & 0.057 & 0.0567 \\
Slope(\%) & 0.069 & 0.0582 \\
Slope direction & 0.042 & 0.03392 \\
Parent rock & 0.051 & 0.0401 \\
Fault distance & 0.039 & 0.0321 \\
Distance from permanent rivers and permanent & 0.028 & 0.03588 \\
aqueducts & 0.048 & 0.0565 \\
Temperature & 0.039 & 0.0395 \\
Distances from the protected areas & 0.057 & 0.0598 \\
Distance from cities & 0.057 & 0.0541 \\
Distances from villages & 0.041 & 0.0498 \\
Land capacity & 0.025 & 0.0415 \\
Distance from airport & 0.023 & 0.0201 \\
Distances from main roads and highways & 0.061 \\
Land uses & 0.05356 \\
Population density & 0.0311 \\
Distance from water transmission lines & 0.03211 \\
Distance from power lines & 0.0389 \\
\hline Distance from existing industries & & \\
\hline & 0.021 & 0.058 \\
\hline
\end{tabular}




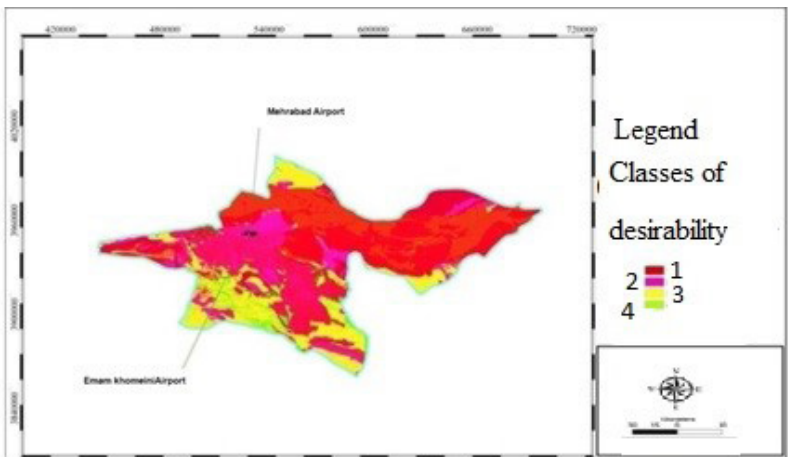

Figure 2. Zoning the airports location in Tehran province using TOPSIS and Weighted Overlay methods (Classes 1 to 4 show the desirability of the airports location, Classes 1 and 4 show the lowest and highest desirability, respectively).

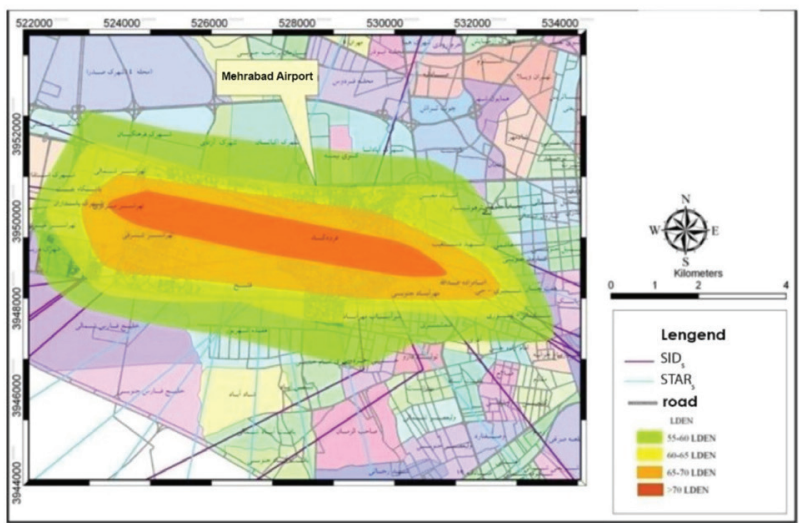

Figure 3. Strategic map of sound factor in Mehrabad Airport using CadnaA Model.

Calculation of the highest percentage of annoyance (\%HA) The basis for observation and evaluation of the noise annoyance level is determined as the percentage of respondents highly annoyed by source (\%HA). The rates of annoyance for each level of noise were measured using the ICBEN 11-point scale. Many studies have been conducted using this scale (53) and all studies performed using this method are stored in the ICBEN's studies bank and can be compared with other studies (54). The high amounts of \%HA percentage as the top three numbers of this scale are considered as 8,9 , and 10 (44). The HA percentages at Imam Khomeini and Mehrabad airports are presented in Table 2. Table 3 shows the HA percentages of the respondents at Imam Khomeini and Mehrabad airports at different levels of Lden $(P<0.0001$ and $P<0.0003$, respectively).

The compatibility rate of different activities and land uses around Mehrabad and Imam Khomeini airports regarding sound levels was determined based on the results obtained from field measurements, CadnaA model, and the questionnaires (considering \%HA in different noise levels). The results are expanded for the whole country. The results of \%HA analysis at different levels of Lden in different uses are presented in Table 3.

Based on the above-mentioned results, the criteria that determine the compatibility rate of different activities regarding sound levels in the airports surrounding areas, are presented in Table 4.

Zoning of the airports location in Tehran province is summarized in 5 categories ( 1 to 5 ), from inappropriate (1) to the most appropriate (5). An area of $8897.2 \mathrm{~km}^{2}$ was placed in category 1 , an area of $1368.8 \mathrm{~km}^{2}$ in category 2, an area of $2323.96 \mathrm{~km}^{2}$ in category 3, and an area of $1095.04 \mathrm{~km}^{2}$ was placed in category 4 . However, there was no desirable land on the 5 th category in Tehran province. Based on the final results of zoning and Map No. 2, the location of Imam Khomeini and Mehrabad airports was assessed, the results are presented in Table 5.

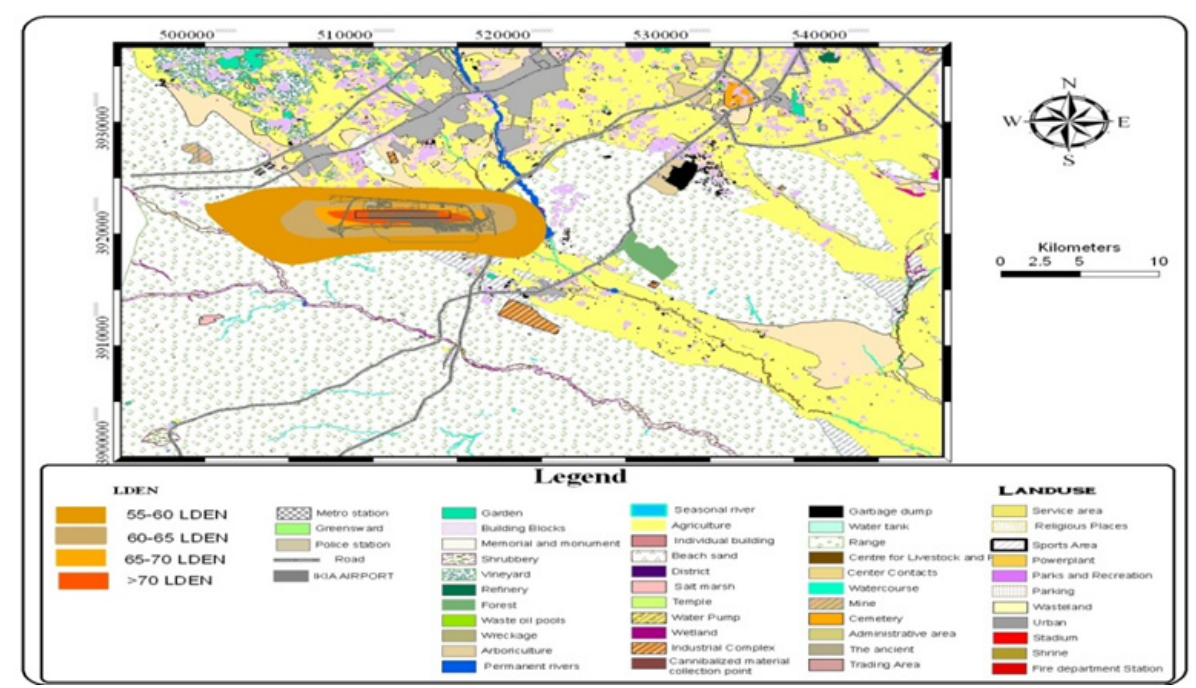

Figure 4. Strategic map of sound factor in Imam Khomeini Airport using CadnaA model. 
Table 2. The \%HA among the respondents in the study areas (Imam Khomeini and Mehrabad airports) at different levels of Lden (Author, 2016)

\begin{tabular}{cccc}
\hline \multicolumn{2}{c}{ Imam Khomeini Airport } & \multicolumn{2}{c}{ Mehrabad Airport } \\
\hline Lden (dB) & \%HA (\%) & Lden (dB) & \%HA (\%) \\
\hline $45-50$ & 8.2 & $45-50$ & 29 \\
$50-55$ & 25 & $50-55$ & 42 \\
$55-60$ & 39 & $55-60$ & 58 \\
$60-65$ & 57 & $60-65$ & 73 \\
$65-70$ & 71 & $65-70$ & 84 \\
$>70$ & 85 & $>70$ & 96.8 \\
\hline
\end{tabular}

\section{Discussion}

Figure 5 shows that at the airports of Imam Khomeini and Mehrabad, with increasing the amount of Lden, the \%HA has a more upward trend than that at the airports studied in the United States, the Netherlands, and Korea. Also, at Lden levels of 55-70, the \%HA reported in the study by Miedema (55) has a more upward trend compared with that reported at Imam Khomeini Airport. But at Mehrabad Airport, at Lden levels up to 65\%, the \%HA has an increasing trend compared with that reported by other studies (56). At Lden levels of 66-70, the \%HA reported in a study in China (57) is higher than that reported at Mehrabad Airport. Also, at Lden levels of 55-75, the increasing trend of \%HA reported in a study in China (2012) is higher than that reported at Imam Khomeini Airport. The innovation of the present study compared to other similar studies $(58,59)$ is the introduction of criteria that determine the compatibility rate of different activities and land uses in the airports surrounding areas while emphasizing on the sound levels obtained from the field measurements, CadnaA model, and the questionnaires feedbacks (considering \%HA at different noise levels). According to Table 5, the location of Mehrabad Airport is not suitable in terms of topography and hydrology,

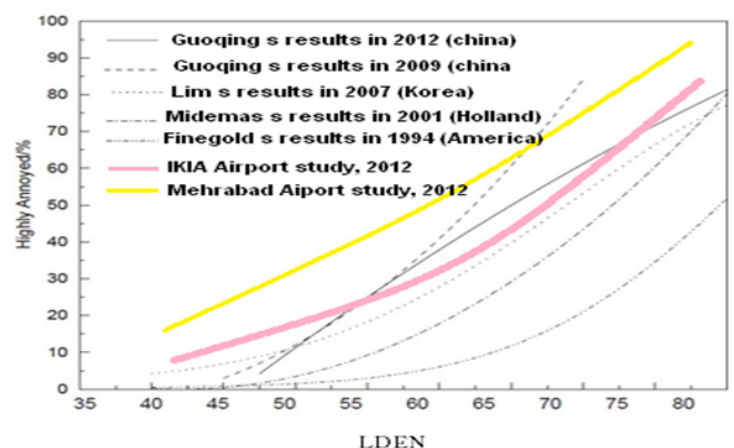

Figure 5. Comparison of the correlation curves between Lden level and $\%$ HA in five countries (Author, 2016).

soil type, and proximity to residential areas. The airport is located in an urban area that is surrounded by the residential, industrial, and commercial areas. It has put not only the residents of surrounding areas at risk, but also has led to air pollution and noise pollution in the area. One of the most important issues at Imam Khomeini airport that has not been taken into account is the passage of aqueducts through the surrounding land, especially under the runway longs, which threatens their strength. In addition to the aqueducts, another significant point that should be considered is the proximity of the airport to the river that in any future development, its drainage will become an important issue.

\section{Conclusion}

According to the results of the present study, the location of Mehrabad and Imam Khomeini airports is considered $60 \%$ and $18 \%$ inappropriate, respectively.

The results indicate that a large-scale zoning for airport establishment is need. The efficiency of the use of the MCDM approach with ArcGIS methods has been

Table 3. Results of HA\% at different levels of Lden in different uses (Author, 2016)

\begin{tabular}{|c|c|c|c|c|c|c|c|c|}
\hline & Lden $40-45$ & Lden $45-50$ & Lden $50-55$ & Lden $55-60$ & Lden $60-65$ & Lden $65-70$ & Lden $>70$ & Lden \\
\hline Residential & 7 & 23 & 39 & 42 & 68 & 76 & 85 & $\% \mathrm{HA}$ \\
\hline Public services & 2 & 10 & 15 & 25 & 32 & 48 & 75 & \\
\hline Commercial & 0 & 4 & 5 & 7 & 21 & 42 & 51 & \\
\hline Industrial and manufacturing & 0 & 1 & 2 & 2 & 5 & 8 & 25 & \\
\hline Recreation and entertainment & 0 & 0 & 3 & 4 & 7 & 15 & 32 & \\
\hline
\end{tabular}

Table 4. Criteria of compatibility rate of land uses regarding sound level in the airports surrounding areas in Iran (Author, 2016)

\begin{tabular}{|c|c|c|c|c|c|c|c|}
\hline Lden $40-45$ & Lden 45-50 & Lden $50-55$ & Lden $55-60$ & Lden $60-65$ & Lden $65-70$ & Lden $>70$ & Lden \\
\hline Residential & $A$ & A1 & B & $\mathrm{B}$ & B & B & B \\
\hline Public services & $A$ & $A$ & A1 & $\mathrm{B}$ & B & B & B \\
\hline Commercial & A & $A$ & A & $A$ & B & B & B \\
\hline Industrial and manufacturing & $A$ & $A$ & $A$ & $A$ & $A$ & B & B \\
\hline Recreation and entertainment & $A$ & $A$ & $A$ & $A$ & A & B & B \\
\hline
\end{tabular}

A: Compatible, B: Incompatible, A1: With noise insulation and controlling the sound levels. 
Table 5. Assessment of the location of Mehrabad and Imam Khomeini airports according to Map No. 2

\begin{tabular}{|c|c|c|}
\hline Criteria & Mehrabad Airport & Emam Khomeini Airport \\
\hline Erodibility & Inappropriate & Inappropriate \\
\hline Soil fertility & Appropriate & Appropriate \\
\hline Soil texture & Appropriate & Appropriate \\
\hline Climate & Appropriate & Appropriate \\
\hline Height (m) & Inappropriate & Inappropriate \\
\hline Slope & Inappropriate & Inappropriate \\
\hline Slope direction & Inappropriate & Appropriate \\
\hline Parent rock & Inappropriate & Appropriate \\
\hline Distance from fault & Inappropriate & Inappropriate \\
\hline Distance from permanent rivers and aqueducts & Inappropriate & Inappropriate \\
\hline Temperature & Appropriate & Appropriate \\
\hline Distance from protected areas & Appropriate & Appropriate \\
\hline Distance from cities & Inappropriate & Appropriate \\
\hline Distance from villages & Appropriate & Appropriate \\
\hline Distance to landfill & Appropriate & Appropriate \\
\hline Distance from airport & Appropriate & Appropriate \\
\hline Distance from main roads and highways & Appropriate & Appropriate \\
\hline Land use & Inappropriate & Appropriate \\
\hline Population density & Inappropriate & Appropriate \\
\hline Distance from water transmission lines & Inappropriate & Appropriate \\
\hline Distance from power transmission lines & Inappropriate & Appropriate \\
\hline Distance from existing industries & Inappropriate & Appropriate \\
\hline
\end{tabular}

extensively confirmed in the recent zoning studies. One of the strengths of this research is the simultaneous field measurements of noise pollution and examining the level of noise annoyance among residents of Mehrabad and Imam Khomeini airports, the results of which led to the introduction of a set of criteria for determining the compatibility rate of different activities around the airports based on the noise levels. The lack of this index was quite significant in the criteria for locating airports in Iran. The indicators can be used in future studies on locating airports in Iran.

\section{Acknowledgments}

The authors would like to express their sincere gratitude to the authorities of Mehrabad and Imam Khomeini International airports for conducting field visits and providing the required data.

\section{Ethical issues}

The authors hereby certify that all data collected during the research are as expressed in the manuscript, and no data from the study has been or will be published elsewhere separately.

\section{Competing interests}

The authors declare that they have no conflict of interests.

\section{Authors' contributions}

All authors have contributed in the study design, field visits, data collection and analysis, and manuscript preparation. The final version of this manuscript was reviewed and confirmed by all authors.

\section{References}

1. Miedema HM, Fields JM, Vos H. Effect of season and meteorological conditions on community noise annoyance. J Acoust Soc Am 2005; 117(5): 2853-65. doi: $10.1121 / 1.1896625$.

2. Nassur AM, Léger D, Lefèvre M, Elbaz M, Mietlicki F, Nguyen P, et al. The impact of aircraft noise exposure on objective parameters of sleep quality: results of the DEBATS study in France. Sleep Med 2019; 54: 70-7. doi: 10.1016/j. sleep.2018.10.013.

3. ICAO. Airport Planning Manual. [cited 2019 Sep 25] Available from: https://docplayer.net/12231317-Manualairport-planning-part-1-master-planning-doe-9184-an902-part-1-international-civil-aviation-organization-0oac. html.

4. Gasco L, Asensio C, de Arcas G. Communicating airport noise emission data to the general public. Sci Total Environ 2017; 586: 836-48. doi: 10.1016/j.scitotenv.2017.02.063.

5. Brown AL, Lam KC, van Kamp I. Quantification of the exposure and effects of road traffic noise in a dense Asian city: a comparison with western cities. Environ Health 2015; 14: 22. doi: 10.1186/s12940-015-0009-8.

6. Tezel MN, Sari D, Erdol M, Hamamci SF, Ozkurt N. Evaluation of some health impact indices in two airports' domain. Appl Acoust 2019; 149: 99-107. doi: 10.1016/j. apacoust.2019.01.014.

7. Wolfe PJ, Kramer JL, Barrett SR. Current and future noise 
impacts of the UK hub airport. J Air Transp Manag 2017; 58: 91-9. doi: 10.1016/j.jairtraman.2016.09.002.

8. Girvin R. Aircraft noise regulation, airline service quality, and social welfare: the monopoly case. Journal of Transport Economics and Policy 2010; 44(1): 17-35. doi: $10.2307 / 40599981$.

9. Otčenášek J. Environmental aircraft take-off noise - sound quality factors associated with unpleasantness. Transp Res D Transp Environ 2019; 67: 366-74. doi: 10.1016/j. trd.2018.10.014.

10. Lawton RN, Fujiwara D. Living with aircraft noise: airport proximity, aviation noise and subjective wellbeing in England. Transp Res D Transp Environ 2016; 42: 104-18. doi: 10.1016/j.trd.2015.11.002.

11. Rodríguez-Díaz A, Adenso-Díaz B, González-Torre PL. Improving aircraft approach operations taking into account noise and fuel consumption. J Air Transp Manag 2019; 77: 46-56. doi: 10.1016/j.jairtraman.2019.03.004.

12. Bartels S, Rooney D, Müller U. Assessing aircraft noiseinduced annoyance around a major German airport and its predictors via telephone survey - the COSMA study. Transp Res D Transp Environ 2018; 59: 246-58. doi: 10.1016/j. trd.2018.01.015.

13. Basner M, Babisch W, Davis A, Brink M, Clark C, Janssen S, et al. Auditory and non-auditory effects of noise on health. Lancet 2014; 383(9925): 1325-32. doi: 10.1016/s01406736(13)61613-x

14. Ahmad SA, Sarkar PK, Dhungana HN. A study of noise \& development of traffic noise annoyance models. Journal of Transportation Technologies 2015; 5(4): 185-90. doi: 10.4236/jtts.2015.54017

15. Salah K. Environmental impact reduction of commercial aircraft around airports. Less noise and less fuel consumption. European Transport Research Review 2014; 6: 71-84. doi: 10.1007/s12544-013-0106-0.

16. Torija AJ, Roberts S, Woodward R, Flindell IH, McKenzie $\mathrm{AR}$, Self RH. On the assessment of subjective response to tonal content of contemporary aircraft noise. Appl Acoust 2019; 146: 190-203. doi: 10.1016/j.apacoust.2018.11.015.

17. Torija AJ, Self RH, Flindell IH. Airport noise modelling for strategic environmental impact assessment of aviation. Appl Acoust 2018; 132: 49-57. doi: 10.1016/j. apacoust.2017.10.017.

18. Blakey M. Airport Noise Compatibility Planning (14 CFR Part 150). Available from: http://www.faa.gov/airports/ environmental/airport_noise.

19. Alvarssona JJ, Nordström H, Lunden P, Nilsson M. Aircraft noise and speech intelligibility in an outdoor living space. J Acoust Soc Am 2014; 135(6): 3455-63. doi: $10.1121 / 1.4874625$.

20. Sennaroglu B, Varlik Celebi G. A military airport location selection by AHP integrated PROMETHEE and VIKOR methods. Transp Res D Transp Environ 2018; 59: 160-73. doi: 10.1016/j.trd.2017.12.022.

21. Flores R, Asensio C, Gagliardi P, Licitra G. Study of the correction factors for aircraft noise façade measurements. Appl Acoust 2019; 145: 399-407. doi: 10.1016/j. apacoust.2018.10.007.

22. Floud S, Blangiardo M, Clark C, de Hoogh K, Babisch W, Houthuijs D, et al. Exposure to aircraft and road traffic noise and associations with heart disease and stroke in six European countries: a cross-sectional study. Environ Health 2013; 12: 89. doi: 10.1186/1476-069x-12-89.

23. Revoredo T, Mora-Camino F, Slama J. A two-step approach for the prediction of dynamic aircraft noise impact. Aerosp Sci Technol 2016; 59: 122-31. doi: 10.1016/j.ast.2016.10.017.

24. Rodríguez-Díaz A, Adenso-Díaz B, González-Torre PL. A review of the impact of noise restrictions at airports. Transp Res D Transp Environ 2017; 50: 144-53. doi: 10.1016/j. trd.2016.10.025.

25. Camara T, Kamsu-Foguem B, Diourte B, Faye JP, Hamadoun O. Management of acoustic risks for buildings near airports. Ecol Inform 2018; 44: 43-56. doi: 10.1016/j. ecoinf.2017.12.007.

26. Girvin R. Aircraft noise-abatement and mitigation strategies. Journal of Air Transport Management 2009; 15(1): 14-22. doi: 10.1016/j.jairtraman.2008.09.012.

27. Durmaz V. Organizational change for the environmentally sustainable airport management. Emerging Markets Journal 2011; 1(2): 13-20. doi: 10.5195/emaj.2011.9.

28. Ganic E, Dobrota M, Babic O. Noise abatement measures at airports: contributing factors and mutual dependence. Appl Acoust 2016; 112: 32-40. doi: 10.1016/j. apacoust.2016.05.007.

29. Phun VK, Hirata T, Yai T. Effects of noise exposure of other people on aircraft noise tolerability using a reference point approach. Transp Res D Transp Environ 2016; 48: 171-86. doi: 10.1016/j.trd.2016.08.012.

30. Beeco JA, Joyce D. Automated aircraft tracking for park and landscape planning. Landsc Urban Plan 2019; 186: 103-11. doi: 10.1016/j.landurbplan.2019.03.001.

31. Alonso G, Benito A, Boto L. The efficiency of noise mitigation measures at European airports. Transportation Research Procedia 2017; 25: 103-35. doi: 10.1016/j. trpro.2017.05.385.

32. Mahashabde A, Wolfe P, Ashok A, Dorbian C, He Q, Fan A, et al. Assessing the environmental impacts of aircraft noise and emissions. Prog Aerosp Sci 2011; 47(1): 15-52. doi: $\quad 10.1016 /$ j.paerosci.2010.04.003.

33. Kroesen M, Molin EJ, Miedema HM, Vos H, Janssen SA, van Wee B. Estimation of the effects of aircraft noise on residential satisfaction. Transp Res D Transp Environ 2010; 15(3): 144-53. doi: 10.1016/j.trd.2009.12.005.

34. Babisch W. Transportation noise and cardiovascular risk: updated review and synthesis of epidemiological studies indicate that the evidence has increased. Noise Health 2006; 8(30): 1-29. doi: 10.4103/1463-1741.32464.

35. Fujiwara D, Lawton RN, MacKerron G. Experience sampling in and around airports. Momentary subjective wellbeing, airports, and aviation noise in England. Transp Res D Transp Environ 2017; 56: 43-54. doi: 10.1016/j. trd.2017.07.015.

36. Sanchez-Perez LA, Sanchez-Fernandez LP, Shaout A, Suarez-Guerra S. Airport take-off noise assessment aimed at identify responsible aircraft classes. Sci Total Environ 2016; 542(Pt A): 562-77. doi: 10.1016/j.scitotenv.2015.10.037.

37. Ko JH, Chang SI, Lee BC. Noise impact assessment by utilizing noise map and GIS: A case study in the city of Chungju, Republic of Korea. Applied Acoustics 2011; 72(8): 544-50. doi: 10.1016/j.apacoust.2010.09.002. 
38. Malczewski J, Rinner C. Multiattribute decision analysis methods. In: Multicriteria Decision Analysis in Geographic Information Science. Advances in Geographic Information Science. Berlin, Heidelberg: Springer; 2015. p. 81-121. doi: 10.1007/978-3-540-74757-4_4.

39. Beskese A, Handan Demir H, Kurtulus Ozcan H, Eser Okten H. Landfill site selection using fuzzy AHP and fuzzy TOPSIS: a case study for Istanbul. Environ Earth Sci 2015; 73(7): 3513-21. doi: 10.1007/s12665-014-3635-5.

40. Pires A, Chang NB, Martinho G. An AHP-based fuzzy interval TOPSIS assessment for sustainable expansion of the solid waste management system in Setúbal Peninsula, Portugal. Resour Conserv Recycl 2011; 56(1): 7-21. doi: 10.1016/j.resconrec.2011.08.004.

41. Lim C, Kim J, Hong J, Lee S, Lee S. The relationship between civil aircraft noise and community annoyance in Korea. Journal of Sound and Vibration 2007; 299(3):575-86. doi: 10.1016/j.jsv.2006.06.064.

42. Fidell S, Mestre V, Schomer P, Horonjeff R, Reid T. Fidell S, et al. A systematic rationale for defining the significance of aircraft noise impacts. J Acoust Soc Am 2014; 136(3): 1129. doi: $10.1121 / 1.4892933$.

43. Houacine M, Khardi S. Gauss Pseudospectral method for less noise and fuel consumption of aircraft operations. Journal of Aircraft 2010; 47(6): 2152-9. doi: 10.2514/1. C031007.

44. Shih HS, Shyur HJ, Lee ES. An extension of TOPSIS for group decision making. Math Comput Model 2007; 45(78): 801-13. doi: $10.1016 / \mathrm{j} . \mathrm{mcm} .2006 .03 .023$.

45. Rao RV, Davim JP. A decision-making framework model for material selection using a combined multiple attribute decision-making method. Int J Adv Manuf Technol 2008; 35(7): 751-60. doi: 10.1007/s00170-006-0752-7.

46. Mostafaee M, Nassiri P, Mostafaee M. Evaluation of noise pollution at Mehrabad airport and noise control plans. Iranian Society of Environment Conference; 2014; Tehran: Sharif University; 2014.

47. Kiani Sadr M, Nassiri P, Hosseini M, Monavari M, Gharagozlou A. Assessment of land use compatibility and noise pollution at Imam Khomeini international airport. J Air Transp Manag 2014; 34: 49-56. doi: 10.1016/j. jairtraman.2013.07.009.

48. Madeira JG, Alvim AC, Martins VB, Monteiro NA. Selection of a tool to decision making for site selection for high level waste. EPJ Nucl Sci Technol 2016; 2(6): 1-8. doi: 10.1051/epjn/e2015-50039-x.

49. de Hollander AE. Assessing and Evaluating the Health Impact of Environmental Exposures [dissertation]. Utrecht: Utrecht University; 2004.

50. Federal Aviation Administration. Integrated Noise Model (INM). [cited 2019 Oct 12] Available from: https://www.faa. gov/about/office_org/headquarters_offices/apl/research/ models/inm_model/.

51. U.S. Department of Transportation Federal Aviation Administration. Noise Standards. USA: FAA; 2017.

52. Azizi A, Malekmohammadi B, Jafari HR, Nasiri H, Amini Parsa V. Land suitability assessment for wind power plant site selection using ANP-DEMATEL in a GIS environment: case study of Ardabil province, Iran. Environ Monit Assess 2014; 186(10): 6695-709. doi: 10.1007/s10661-014-3883-6.

53. Taskin Gumus A, Yilmaz G. Sea vessel type selection via an integrated VAHP-ANP methodology for high-speed public transportation in Bosphorus. Expert Syst Appl 2010; 37(6): 4182-9. doi: 10.1016/j.eswa.2009.11.005.

54. Johnson TA, Cooper S, Stamper GC, Chertoff M. Noise exposure questionnaire: a tool for quantifying annual noise exposure. J Am Acad Audiol 2017; 28(1): 14-35. doi: 10.3766/jaaa.15070.

55. Miedema HM. Annoyance caused by environmental noise: elements for evidence-based noise policies. J Soc Issues 2007; 63(1): 41-57. doi: 10.1111/j.1540-4560.2007.00495.x.

56. Kroesen M, Molin EJ, van Wee B. Measuring subjective response to aircraft noise: the effects of survey context. J Acoust Soc Am 2013; 133(1): 238-46. doi: $10.1121 / 1.4768795$.

57. Gómez-Navarro T, García-Melón M, Acuña-Dutra S, DíazMartín D. An environmental pressure index proposal for urban development planning based on the analytic network process. Environ Impact Assess Rev 2009; 29(5): 319-29. doi: 10.1016/j.eiar.2008.10.004.

58. Vogiatzis K. Airport environmental noise mapping and land use management as an environmental protection action policy tool. The case of the Larnaka International Airport (Cyprus). Sci Total Environ 2012; 424: 162-73. doi: 10.1016/j.scitotenv.2012.02.036.

59. Zaporozhets O, Tokarev V, Attenborough K. Aircraft Noise: Assessment, Prediction and Control. New York: Spon Press; 2011. p. 433. 